\title{
Respiração, produção de etileno e qualidade de maçãs “Gala” em função do dano mecânico por impacto e da aplicação de 1-metilciclopropeno
}

\author{
Respiration, ethylene production and quality of 'Gala' apples in function to impact injury and \\ treatment with 1-methylcyclopropene
}

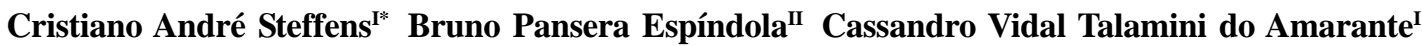 João Paulo Generoso SilveiraII Ricardo Chechi' ${ }^{\text {II }}$ Auri Brackmann"II}

\section{RESUMO}

O objetivo deste trabalho foi avaliar o efeito do dano mecânico por impacto e da aplicação de 1metilciclopropeno sobre a atividade respiratória e a taxa de produção de etileno e a qualidade físico-química de maçãs "Gala”, após o armazenamento em atmosfera controlada. Os tratamentos avaliados foram $T_{1}$ : controle; $T_{2}$ : dano mecânico; $T_{3}$ : 1-metilciclopropeno; $T_{4}$ : dano mecânico +1 metilciclopropeno; e $T_{5}$ : 1-metilciclopropeno + dano mecânico. Após a aplicação dos tratamentos, os frutos foram armazenados sob condição ambiente ( $20 \pm 2^{\circ} \mathrm{C} / 65 \pm 5 \%$ UR). Os frutos submetidos ao dano mecânico e não tratados com 1metilciclopropeno apresentaram um maior incremento na produção de etileno. O tratamento dano mecânico não aumentou a atividade respiratória e pouco influenciou o amadurecimento dos frutos, comparado ao controle, porém, aumentou a ocorrência de podridões. O 1-metilciclopropeno reduziu o metabolismo e a perda de qualidade dos frutos. Nos frutos submetidos ao dano mecânico, a aplicação de 1metilciclopropeno reduziu a incidência de podridões.

Palavras-chave: Malus domestica Bork., pós-colheita, armazenamento, metabolismo, qualidade.

\section{ABSTRACT}

The objective of this research was to evaluate the effect of the impact injury and treatment with 1methylcyclopropene on respiration and ethylene production rates and on quality of 'Gala' apples after the storage in controlled atmosphere. The treatments evaluated were: $T_{1}$ : control, $T_{2}$ : mechanical injury; $T_{3}$ : 1-methylcyclopropene; $T_{4}$ : mechanical injury + 1-methylcyclopropene; and $T_{5}: 1$ methylcyclopropene + mechanical injury. Fruits were then left at ambient conditions $\left(20 \pm 2{ }^{\circ} \mathrm{C} / 65 \pm 5 \%\right.$ RH). Fruits submitted to mechanical injury, without the treatment with 1methylcyclopropene, showed the highest increment of ethylene production. The mechanical injury did not increase the respiratory rate and had small effect on fruit ripening, compared to the control treatment, but increased rot incidence. The 1methylcyclopropene reduced the metabolism and the loss of fruit quality. In fruits submitted to mechanical injury, the application 1-methylcyclopropene reduced rot incidence.

Key words: Malus domestica Bork., postharvest, storage, metabolism, quality.

\section{INTRODUÇÃO}

A maçã é uma espécie que possui uma vida pós-colheita longa, comparativamente a outras espécies de frutos, podendo ser armazenada, em atmosfera controlada, por até nove meses. No entanto, apesar do grande potencial de armazenamento desta cultivar, seu amadurecimento pode ser acelerado devido aos danos mecânicos que ocorrem durante o processo de classificação, transporte e principalmente na fase de comercialização.

Não existem informações sobre a intensidade de perdas que ocorrem em maçã decorrentes de danos mecânicos. No entanto, nos produtos hortícolas em geral, estima-se uma perda de 20 a $25 \%$, dependendo da sensibilidade do produto e da intensidade do dano (VIGNEAULT et al., 2002).

'Departamento de Fitotecnia, Universidade do Estado de Santa Catarina (UDESC). Av. Luis de Camões, 2090, Bairro Conta Dinheiro, 88520-000, Lages, SC, Brasil. E-mail: steffens@cav.udesc.br. *Autor para correspondência.

"Curso de Agronomia, UDESC, Lages, SC, Brasil.

IIIDepartamento de Fitotecnia, Universidade Federal de Santa Maria (UFSM), Santa Maria, RS, Brasil. 
O dano mecânico causa um estresse no fruto, reduzindo seu valor comercial. $\mathrm{O}$ dano pode ser oriundo de fricção, compressão ou impacto (CHITARRA $\&$ CHITARRA, 2005). No dano por impacto, geralmente há a contusão, expondo o suco celular ao ar, quando ocorre a oxidação e o posterior escurecimento da polpa e o aumento da atividade respiratória e da produção de etileno (MATTIUZ \& DURIGAN, 2001; DURIGAN et al., 2005; DE MARTINO et al., 2006). Como o etileno está relacionado com a indução dos processos envolvidos no amadurecimento dos frutos, a maior produção de etileno, desencadeada pelo dano mecânico, pode acelerar o processo de amadurecimento, reduzindo a vida pós-colheita dos frutos.

O 1-metilciclopropeno pode ser uma alternativa para inibir a indução do amadurecimento dos frutos desencadeado pelo dano mecânico, visto que é um potente inibidor da ação do etileno (DAL CIN et al., 2006). O 1-metilciclopropeno aumenta o período de conservação de maçãs, sendo este efeito devido à inibição da ação do etileno no fruto (BRACKMANN et al., 2004; CURRENT et al., 2005). Além disso, a aplicação de 1-metilciclopropeno em damascos inibiu a indução do amadurecimento ocasionado pelo dano mecânico por impacto (DE MARTINO et al., 2006). No entanto, não existem informações sobre o efeito do 1metilciclopropeno no controle do amadurecimento em frutos submetidos ao dano mecânico.

Desse modo, este trabalho teve como objetivo avaliar os efeitos do dano mecânico por impacto e da aplicação de 1-metilciclopropeno sobre a atividade respiratória, a produção de etileno e a qualidade físico-química de maçãs "Gala", após o armazenamento em atmosfera controlada.

\section{MATERIAL E MÉTODOS}

As maçãs "Gala" foram colhidas em pomar comercial localizado no município de Lages, Santa Catarina (SC), e armazenados em atmosfera controlada $\left(0,5 \pm 0,2^{\circ} \mathrm{C} / 1,5 \mathrm{kPa} \mathrm{O}_{2}+2,5 \mathrm{kPa} \mathrm{CO}_{2} / 90-95 \% \mathrm{UR}\right)$ durante sete meses, antes da realização do experimento. Os frutos foram classificados mecanicamente, selecionando-se aqueles livres de ferimentos ou danos mecânicos e transportados para o Laboratório de Pesquisa Pós-colheita do Centro de Ciências Agroveterinárias da Universidade do Estado de Santa Catarina, em Lages, SC.

O delineamento experimental foi $o$ inteiramente casualizado, sendo utilizadas quatro repetições por tratamento e unidade experimental composta por 20 frutos, sendo que para as análises da atividade respiratória e da taxa de produção de etileno foram utilizados dez frutos. Os tratamentos utilizados foram $\mathrm{T}_{1}$ : controle; $\mathrm{T}_{2}$ : dano mecânico; $\mathrm{T}_{3}: 1$ metilciclopropeno; $\mathrm{T}_{4}$ : dano mecânico +1 metilciclopropeno; e $\mathrm{T}_{5}$ : 1-metilciclopropeno + dano mecânico. $\mathrm{O}$ dano mecânico por impacto foi realizado por meio da queda livre do fruto de uma altura de $0,2 \mathrm{~m}$ sobre uma superfície plana indeformável. Cada fruto recebeu duas quedas em lados opostos, na região equatorial. Como fonte de 1-metilciclopropeno, foi utilizado o produto Smart Fresh ${ }^{\circledR}(0,14 \%$ de 1 metilciclopropeno na formulação pó) na relação de $1,0 \mathrm{~g}$ de produto por metro cúbico de câmara para obter $625 \mu \mathrm{L}$ $\mathrm{L}^{-1}$ de 1-metilciclopropeno na atmosfera do local de aplicação. O produto foi solubilizado em água a temperatura ambiente em um recipiente hermético e, posteriormente, a solução foi transferida para uma placa de petri dentro de um refrigerador, com volume de 280 litros, com imediato fechamento deste. Os frutos ficaram expostos ao tratamento por 24 horas.

Antes da aplicação dos tratamentos, três amostras de 10 frutos foram analisadas para determinar a condição inicial média das maçãs, sendo que os frutos apresentavam firmeza de polpa de $55,4 \mathrm{~N}$, sólidos solúveis totais de $16,0^{\circ}$ Brix, acidez titulável de $7,36 \mathrm{meq}$ $100 \mathrm{~mL}^{-1} \mathrm{e}$ cor da epiderme de $84,4^{\circ} \mathrm{h}$ (ângulo hue).

Após a aplicação dos tratamentos, os frutos foram colocados em bandejas e deixados em condição ambiente $\left(20-21^{\circ} \mathrm{C}\right.$ e $65 \pm 5 \%$ de UR), durante nove dias. As análises de firmeza de polpa, acidez titulável, cor da epiderme, sólidos solúveis totais, ocorrência de polpa farinácea, podridões e degenerescência da polpa foram realizadas após cinco e nove dias. As quantificações da atividade respiratória e da taxa de produção de etileno foram feitas após um, três, cinco, sete e nove dias.

A atividade respiratória e a taxa de produção de etileno foram quantificadas, colocando dez frutos de cada amostra em um recipiente com o volume de $4.100 \mathrm{~mL}$, que permite fechamento hermético. A atividade respiratória foi obtida pela diferença da concentração de CO no interior do recipiente, imediatamente após o seu fechamento e depois de uma hora. Alíquotas de gás $(1 \mathrm{~mL})$ foram retiradas dos recipientes por meio de um septo e injetadas em um cromatógrafo a gás Varian ${ }^{\circledR}$, modelo CP-3800, possuindo coluna Porapak $\mathrm{N}^{\circledR}$ de $3 \mathrm{~m}$ (80-100mesh), metanador e detector de ionização de chama. As temperaturas da coluna, do detector, do metanador e do injetor foram de $45^{\circ} \mathrm{C}, 120^{\circ} \mathrm{C}, 300^{\circ} \mathrm{C}$ e $110^{\circ} \mathrm{C}$, respectivamente. Os fluxos de nitrogênio, hidrogênio e ar sintético foram de 70, 30 e 300 $\mathrm{mL} \mathrm{min}^{-1}$, respectivamente. Os valores da atividade respiratória e da taxa de produção de etileno foram calculados por 
meio da fórmula obtida por BANKS et al. (1995) e expressos em nmol de $\mathrm{CO}_{2} \mathrm{~kg}^{-1} \mathrm{~s}^{-1}$ e pmol de $\mathrm{C}_{2} \mathrm{H}_{4} \mathrm{~kg}^{-1}$ $\mathrm{s}^{-1}$, respectivamente.

A determinação da cor da epiderme foi efetuada com um colorímetro Minolta, modelo CR 400, sendo as leituras realizadas em dois lados do fruto, na região equatorial. Na análise realizada antes da colheita, a cor da epiderme foi determinada em termos de ângulo hue para caracterizar o estádio de maturação dos frutos antes da realização do experimento. Nos tratamentos com dano mecânico, a leitura foi realizada nas regiões que sofreram lesão, sendo obtidos os valores de luminosidade $(L)$, que varia de zero (preto) a 100 (branco), para evidenciar o efeito do dano mecânico no escurecimento do tecido.

A firmeza de polpa foi determinada na região equatorial dos frutos, em dois lados opostos, após remoção de uma pequena porção da epiderme e com auxílio de um penetrômetro equipado com ponteira de $11 \mathrm{~mm}$ de diâmetro, sendo os resultados expressos em Newton (N).

Os valores de acidez titulável foram obtidos por meio de uma amostra de $10 \mathrm{~mL}$ de suco dos frutos, previamente extraído de fatias transversais retiradas da região equatorial das maçãs e trituradas em uma centrífuga elétrica. Esta amostra foi diluída em 100mL de água destilada e titulada com solução de hidróxido de sódio $0,1 \mathrm{~N}$ até $\mathrm{pH} 8,1$, sendo os resultados expressos em meq $100 \mathrm{~mL}^{-1}$. Os teores de sólidos solúveis totais foram determinados por refratometria, utilizando-se o suco extraído conforme descrito para a acidez titulável, sendo realizada a correção do efeito da temperatura $\left(20^{\circ} \mathrm{C}\right)$ e os resultados expressos em ${ }^{\circ}$ Brix.

A avaliação da degenerescência interna foi realizada por meio de corte na secção transversal dos frutos, sendo feita a contagem dos frutos que apresentavam regiões internas da polpa com qualquer tipo de escurecimento de aspecto umedecido, sendo os resultados expressos em percentagem.

A polpa farinácea foi determinada pela quantificação dos frutos que apresentavam sintomas como polpa seca e pouca suculência. A ocorrência de podridões foi avaliada por meio da contagem dos frutos afetados, interna e externamente, com lesões maiores do que $5 \mathrm{~mm}$ de diâmetro causadas por patógenos, sendo os resultados expressos em percentagem.

Os dados foram submetidos à análise da variância (ANOVA). Dados em porcentagem foram transformados pela fórmula $\operatorname{arc}$. sen $\sqrt{x / 100}$ antes de serem submetidos à ANOVA. Para a comparação das médias, adotou-se o teste de Tukey com $5 \%$ de significância.

\section{RESULTADOS E DISCUSSÃO}

A atividade respiratória apresentou diferença entre os tratamentos aos sete e aosnove dias após o início do experimento, sendo que os tratamentos controle e dano mecânico apresentaram atividade respiratória mais elevada equivalendo a 414,3 e $420,4 \mathrm{nmol}$ de $\mathrm{CO}_{2} \mathrm{~kg}^{-1} \mathrm{~s}^{-1}$, respectivamente, ao nono dia (Tabela 1). Observou-se que o dano mecânico não aumentou a atividade respiratória dos frutos em relação ao tratamento controle. Este resultado contraria os resultados obtidos em goiabas "Paluma" e "Pedro Sato" (MATTIUZ \& DURIGAN, 2001) e em lima ácida "Tahiti" (DURIGAN et al., 2005). Entretanto, em damasco, também não foi observado efeito do dano mecânico no aumento da atividade respiratória (DE MARTINO et al., 2006). Possivelmente, a diferença entre os dados encontrados no presente trabalho e nos trabalhos realizados por MATTIUZ \& DURIGAN (2001) e DURIGAN et al. (2005) esteja relacionada à diferente intensidade do dano mecânico e a diferenças de sensibilidade entre as espécies de frutos. Os frutos tratados com 1-metilciclopropeno apresentaram menor atividade respiratória (Tabela 1), o que está de acordo com resultados obtidos em diversos trabalhos (SAFTNER et al., 2003; BRACKMANN et al., 2004; DAL CIN et al., 2006; DE MARTINO et al., 2006). WATKINS (2006) cita que o 1-metilciclopropeno diminui a atividade respiratória dos frutos, especialmente em frutos climatéricos, em que o aumento da respiração é acompanhado pelo aumento da produção de etileno.

Com relação à produção de etileno, observase que o pico de produção de etileno foi observado somente nos frutos do tratamento controle, atingindo

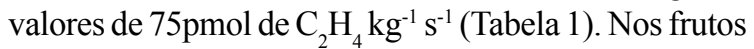
submetidos somente ao dano mecânico, a produção de etileno aumentou exponencialmente após cinco dias de exposição dos frutos à temperatura ambiente, atingindo, no último dia de análise, valores de 164,1pmol de $\mathrm{C}_{2} \mathrm{H}_{4} \mathrm{~kg}^{-1} \mathrm{~s}^{-1}$, não sendo possível detectar pico de produção de etileno (Tabela 1). Os tratamentos 1metilciclopropeno e 1-metilciclopropeno + dano mecânico somente apresentaram incremento na produção de etileno após nove dias de exposição dos frutos à temperatura ambiente, atingindo valores máximos de 44,8 e 28,3pmol de $\mathrm{C}_{2} \mathrm{H}_{4} \mathrm{~kg}^{-1} \mathrm{~s}^{-1}$, respectivamente (Tabela 1 ). $\mathrm{O}$ tratamento dano mecânico + 1-metilciclopropeno não apresentou incremento na atividade de produção de etileno durante o período de avaliação, mantendo os valores próximos de 2 pmol de $\mathrm{C}_{2} \mathrm{H}_{4} \mathrm{~kg}^{-1} \mathrm{~s}^{-1}$ (Tabela 1). Vários trabalhos têm demonstrado que o 1-metilciclopropeno tem forte 
Tabela 1 - Atividade respiratória e taxa de produção de etileno de maçãs "Gala" em função do dano mecânico por impacto e da aplicação de 1-metilciclopropeno (1-MCP).

\begin{tabular}{|c|c|c|c|c|c|}
\hline \multirow{3}{*}{ Tratamentos } & \multicolumn{5}{|c|}{-------------Dias de armazenamento dos frutos a temperatura ambiente-------------- } \\
\hline & \multicolumn{5}{|c|}{----------------------Atividade respiratória (nmol de $\mathrm{CO}_{2} \mathrm{~kg}^{-1} \mathrm{~s}^{-1}$ ) ------------------- } \\
\hline & 1 & 3 & 5 & 7 & 9 \\
\hline Controle & $91,5 \mathrm{a}$ & $252,8 \mathrm{a}$ & $237,7 \mathrm{a}$ & $235,7 \mathrm{a}$ & $414,3 \mathrm{a}$ \\
\hline Dano mecânico & $80,0 \mathrm{a}$ & $185,2 \mathrm{a}$ & $272,4 \mathrm{a}$ & $242,1 \mathrm{a}$ & $420,4 \mathrm{a}$ \\
\hline 1-MCP & $90,5 \mathrm{a}$ & $224,3 \mathrm{a}$ & $206,9 a$ & $182,7 \mathrm{~b}$ & $298,0 b$ \\
\hline Dano mecânico + 1-MCP & $87,4 \mathrm{a}$ & $195,2 \mathrm{a}$ & $201,9 a$ & $145,8 b$ & $253,8 b$ \\
\hline 1-MCP + dano mecânico & $103,4 \mathrm{a}$ & $214,6 a$ & $246,7 \mathrm{a}$ & $187,4 b$ & $297,2 b$ \\
\hline $\mathrm{CV}(\%)$ & 15,1 & 9,10 & 15,3 & 8,88 & 14,6 \\
\hline \multicolumn{6}{|c|}{ Taxa de produção de etileno (pmol kg $\left.{ }^{-1} \mathrm{~s}^{-1}\right)$} \\
\hline Controle & $33,8 \mathrm{a}$ & $34,0 \mathrm{a}$ & $36,3 \mathrm{a}$ & $75,0 \mathrm{a}$ & $36,3 b$ \\
\hline Dano mecânico & $34,6 a$ & $34,7 \mathrm{a}$ & $48,1 \mathrm{a}$ & $102,4 \mathrm{a}$ & $164,1 \mathrm{a}$ \\
\hline 1-MCP & $2,3 b$ & $2,3 b$ & $2,3 b$ & $4,2 b$ & $44,8 b$ \\
\hline Dano mecânico + 1-MCP & $2,4 b$ & $2,4 \mathrm{~b}$ & $2,4 \mathrm{~b}$ & $2,3 b$ & $2,4 \mathrm{~b}$ \\
\hline 1-MCP + dano mecânico & $2,8 b$ & $2,8 \mathrm{~b}$ & $2,5 b$ & $2,3 b$ & $28,3 b$ \\
\hline CV (\%) & 79,4 & 79,5 & 40,1 & 38,2 & 41,1 \\
\hline
\end{tabular}

*Médias não seguidas pela mesma letra diferem pelo teste de Tukey em nível de 5\% de significância.

efeito sobre a redução da produção de etileno (BRACKMANN et al., 2004; DAL CIN et al., 2006; DE MARTINO et al., 2006). DAL CIN et al. (2006) observaram que a menor produção de etileno em maçãs tratadas com 1-metilciclopropeno está relacionada à menor produção de transcritos das enzimas consideradas chave na regulação da síntese de etileno, 1-aminociclopropano carboxilase sintase e 1aminociclopropano carboxilase oxidase, e dos receptores de etileno, ETR1 e ERS1. WATKINS (2006) afirma que o 1-metilciclopropeno também reduz a atividade das enzimas 1-aminociclopropano carboxilase sintase e 1-aminociclopropano carboxilase oxidase.

Os frutos que sofreram o dano mecânico e que não foram tratados com 1-metilciclopropeno apresentaram, na avaliação realizada aos nove dias, a maior atividade de produção de etileno (Tabela 1). DE MARTINO et al. (2006) observaram comportamento semelhante em damasco. BHOWMIK \& MATSUI(2005) verificaram que o aumento na produção de etileno, induzida por ferimentos, coincide com o incremento na atividade e na síntese de transcritos de 1aminociclopropano carboxilase sintase. Observou-se também que o 1-metilciclopropeno inibiu a indução da produção de etileno pelo dano mecânico (Tabela 1), confirmando resultados reportados em trabalho realizado com damasco (DE MARTINO et al., 2006).

A firmeza de polpa, acidez titulável e sólidos solúveis totais não apresentaram diferenças entre os tratamentos na avaliação realizada após cinco dias de exposição dos frutos à temperatura ambiente (Tabela 2). Todavia, ao nono dia, os maiores valores de firmeza de polpa e acidez titulável foram observados nos frutos tratados com 1-metilciclopropeno (Tabela 2). Com relação à firmeza de polpa, DE MARTINO et al. (2006) também observaram maiores valores de firmeza de polpa em damasco tratados com 1-metilciclopropeno, destacando o efeito desta substância em inibir o amadurecimento induzido pelo dano mecânico. A maior firmeza de polpa nos tratamentos com 1metilciclopropeno está diretamente relacionada à redução na produção e à ação do fitormônio etileno. A presença de etileno é necessária para a atividade das enzimas responsáveis pela perda de firmeza de polpa (JOHNSTON et al., 2001; MAJUMDER \& MAZUMDAR, 2002). MAJUMDER \& MAZUMDAR (2002) constataram que o aumento na atividade da poligalacturonase foi altamente correlacionado com a evolução de etileno. Com relação à acidez titulável, BRACKMANN et al. (2004) e CURRENT et al. (2005) também observaram maior acidez titulável em maçãs tratadas com 1-metilciclopropeno.

Os sólidos solúveis totais não foram diferentes entre os tratamentos nas duas avaliações (Tabela 2). BRACKMANN et al. (2004) também não constataram efeito do 1-metilciclopropeno sobre os teores de sólidos solúveis totais em maçãs "Gala". O dano mecânico também não ocasionou modificações nos teores de sólidos solúveis totais em goiabas "Paluma" e "Pedro Sato" (MATTIUZ \& DURIGAN, 2001) e em damascos (DE MARTINO et al., 2006). 
Tabela 2 - Atributos físico-químicos da maçãs "Gala" em função do dano mecânico por impacto e da aplicação de 1-metilciclopropeno (1$\mathrm{MCP})$.

\begin{tabular}{|c|c|c|c|c|}
\hline Tratamentos & Firmeza de polpa $(\mathrm{N})$ & $\begin{array}{l}\text { Acidez titulável } \\
\left(\text { meq } 100 \mathrm{~mL}^{-1}\right)\end{array}$ & $\begin{array}{l}\text { Sólidos Solúveis Totais } \\
\text { ( }{ }^{\circ} \text { Brix) }\end{array}$ & Cor da epiderme (L) \\
\hline Controle & $65,6 a$ & $5,63 \mathrm{a}$ & $15,0 \mathrm{a}$ & $70,8 \mathrm{a}$ \\
\hline Dano mecânico & $65,2 \mathrm{a}$ & $5,44 \mathrm{a}$ & $15,0 \mathrm{a}$ & $55,8 \mathrm{c}$ \\
\hline 1-MCP & $66,0 \mathrm{a}$ & $5,67 \mathrm{a}$ & $15,2 \mathrm{a}$ & $68,9 \mathrm{a}$ \\
\hline Dano mecânico + 1-MCP & $64,5 \mathrm{a}$ & $5,45 \mathrm{a}$ & $15,5 \mathrm{a}$ & $59,5 \mathrm{~b}$ \\
\hline 1-MCP + dano mecânico & $63,3 \mathrm{a}$ & $5,60 \mathrm{a}$ & $15,1 \mathrm{a}$ & $57,0 \mathrm{c}$ \\
\hline \multirow[t]{2}{*}{$\mathrm{CV}(\%)$} & 3,03 & 4,14 & 2,03 & 2,21 \\
\hline & ------ & ----nove dias a & dano mecânico------------ & ---------------- \\
\hline Controle & $55,2 \mathrm{bc}$ & $5,02 \mathrm{~b}$ & $15,0 \mathrm{a}$ & $67,1 \mathrm{a}$ \\
\hline Dano mecânico & $54,3 \mathrm{c}$ & $5,06 \mathrm{~b}$ & $14,4 \mathrm{a}$ & $54,1 b$ \\
\hline 1-MCP & $60,0 \mathrm{a}$ & $5,26 \mathrm{ab}$ & $14,0 \mathrm{a}$ & $67,1 \mathrm{a}$ \\
\hline Dano mecânico + 1-MCP & $58,0 \mathrm{ab}$ & $5,49 \mathrm{a}$ & $14,4 \mathrm{a}$ & $55,9 \mathrm{~b}$ \\
\hline 1-MCP + dano mecânico & $57,5 \mathrm{ab}$ & $5,24 \mathrm{ab}$ & $14,4 \mathrm{a}$ & $57,3 b$ \\
\hline $\mathrm{CV}(\%)$ & 3,30 & 3,57 & 11,2 & 3,76 \\
\hline
\end{tabular}

*Médias não seguidas pela mesma letra diferem pelo teste de Tukey em nível de 5\% de significância.

O valor de $\mathrm{L}$ nos tratamentos que receberam o impacto foi significativamente menor em ambas as avaliações (Tabela 2), caracterizando o escurecimento da região lesionada. $\mathrm{O}$ escurecimento ocorre devido ao dano no sistema de membranas, levando à descompartimentalização das células da polpa na região lesionada e, assim, à oxidação dos compostos fenólicos.

$\mathrm{Na}$ avaliação realizada aos cinco dias de exposição dos frutos em temperatura ambiente, o tratamento dano mecânico +1 -metilciclopropeno apresentou valores de $\mathrm{L}$ maiores que aqueles que somente sofreram dano ou quando a aplicação de 1metilciclipropeno foi realizada antes do dano mecânico (Tabela 2). Em damascos, o surgimento de uma região escurecida na região lesionada foi retardado pelo 1metilciclopropeno (DE MARTINO et al., 2006). O 1metilciclopropeno diminui a atividade da enzima polifenoloxidase (PESIS et al., 2002; WATKINS, 2006), o que pode explicar a redução no escurecimento decorrente do dano mecânico. No entanto, o tratamento com a aplicação de 1-metilciclopropeno, antes do dano mecânico, não diminuiu o escurecimento na região lesionada (Tabela 2). Talvez esta diferença de resultado entre a aplicação de 1-metilciclopropeno antes ou depois do dano mecânico esteja relacionada à formação de novos receptores de etileno induzidos pelo dano mecânico, permitindo que o etileno se ligue a estes novos receptores, desencadeando maior atividade da enzima polifenoloxidase.

Não houve diferença entre tratamentos quanto à incidência de podridões e de polpa farinácea, avaliada no quinto dia, e de degenerescência da polpa, avaliada aos cinco e aos nove dias de permanência dos frutos a temperatura ambiente (Tabela 3 ). Na análise realizada aos nove dias de exposição dos frutos à temperatura ambiente, o tratamento com 1metilciclopropeno sem dano mecânico apresentou os menores valores de incidência de podridões (Tabela 3). Já o tratamento dano mecânico apresentou a maior incidência de podridões. No entanto, o 1 metilciclopropeno, aplicado antes ou após o dano mecânico, diminuiu a incidência de podridões (Tabela 3). SAFTNER et al. (2003) e BRACKMANN et al. (2004) também encontraram menor ocorrência de podridões em frutos tratados com 1-metilciclopropeno. LIU et al. (2005) sugerem que o 1-metilciclopropeno reduz a ocorrência de podridões em frutos por meio do aumento na atividade das enzimas fenilalanina amônia liase e peroxidase, as quais estão associadas ao mecanismo de defesa vegetal. No entanto, SAFTNER et al. (2003) e BRACKMANN et al. (2004) atribuíram a menor ocorrência de podridões com a aplicação de 1metilciclopropeno à maior firmeza de polpa dos frutos, o que confere maior resistência à infecção. $O$ tratamento com dano mecânico apresentou maior incidência de podridões, o que pode estar relacionado à menor firmeza de polpa (Tabela 2), reduzindo assim a resistência à infecção.

A incidência de polpa farinácea, distúrbio fisiológico relacionado com a senescência dos frutos, foi menor nos tratamentos com 1-metilciclopropeno na avaliação realizada aos nove dias de exposição dos 
Tabela 3 - Ocorrência de podridão e de distúrbios fisiológicos em maçãs "Gala" em função do dano mecânico por impacto e da aplicação de 1-metilciclopropeno (1-MCP)

\begin{tabular}{|c|c|c|c|}
\hline & Podridão (\%) & Degenerescência da polpa (\%) & Polpa farinácea $(\%)$ \\
\hline Controle & $3,3 \mathrm{a}$ & $5,59 \mathrm{a}$ & $3,93 \mathrm{a}$ \\
\hline Dano mecânico & $0,0 \mathrm{a}$ & $9,80 \mathrm{a}$ & $2,08 \mathrm{a}$ \\
\hline 1-MCP & $16,8 \mathrm{a}$ & $6,85 \mathrm{a}$ & $0,00 \mathrm{a}$ \\
\hline Dano mecânico + 1-MCP & $1,8 \mathrm{a}$ & $0,00 \mathrm{a}$ & $1,96 \mathrm{a}$ \\
\hline 1-MCP + dano mecânico & $0,0 \mathrm{a}$ & $1,67 \mathrm{a}$ & $0,00 \mathrm{a}$ \\
\hline $\mathrm{CV}(\%)$ & 86,0 & 60,4 & 87,9 \\
\hline Controle & $12,8 b$ & $\begin{array}{l}\text { ove dias após o dano mecânico } \\
\qquad 0,00 \mathrm{a}\end{array}$ & 40,5a \\
\hline Dano mecânico & $28,1 \mathrm{a}$ & $0,00 \mathrm{a}$ & $38,6 \mathrm{a}$ \\
\hline 1-MCP & $3,5 \mathrm{c}$ & $1,67 \mathrm{a}$ & $11,3 b$ \\
\hline Dano mecânico + 1-MCP & $12,8 b$ & $1,85 \mathrm{a}$ & $12,1 \mathrm{~b}$ \\
\hline 1-MCP + dano mecânico & $12,8 b$ & $1,85 \mathrm{a}$ & $21,0 \mathrm{ab}$ \\
\hline $\mathrm{CV}(\%)$ & 24,0 & 73,7 & 24,3 \\
\hline
\end{tabular}

*Médias não seguidas pela mesma letra diferem pelo teste de Tukey em nível de 5\% de significância.

frutos a temperatura ambiente (Tabela 3). Isso confirma resultados publicados por outros autores, mostrando redução na ocorrência de distúrbios fisiológicos relacionados com a senescência dos frutos por meio da aplicação de 1-metilciclopropeno (WATKINS et al., 2006; BRACKMANN et al., 2004; CURRENT et al., 2005). A redução da ocorrência de distúrbios fisiológicos por esta substância está no fato dela inibir a ação do fitormônio etileno, o qual geralmente aumenta a incidência destes distúrbios por acelerar o processo de senescência.

\section{CONCLUSÕES}

O 1-metilciclopropeno reduz a produção de etileno, diminui a atividade respiratória dos frutos e retarda o pico de produção de etileno, bem como mantém a qualidade dos frutos. O dano mecânico causa um grande incremento na produção de etileno e compromete a qualidade dos frutos. A utilização do 1metilciclopropeno inibe a síntese de etileno e diminui a incidência de podridões nos frutos que sofreram dano mecânico, constituindo-se em uma alternativa para minimizar as perdas induzidas pelos danos mecânicos que possam ocorrer durante a colheita, o transporte, a classificação e a comercialização dos frutos.

\section{REFERÊNCIAS}

BANKS, N.H. et al. Proposal for a rationalized system of units for postharvest research in gas exchange. HortScience, Alexandria, v.30, n.6, p.1129-1131.
BHOWMIK, P.K.; MATSUI, T. Ethylene biosynthetic genes in ,Moso' bamboo shoot in response to wounding. Postharvest Biology and Technology, Amsterdam, n.38, p.188-194, 2005.

BRACKMANN, A. et al. Qualidade da maçã cv. Gala tratada com 1-metilciclopropeno. Ciência Rural, Santa Maria, v.34, n.5, p.1415-1420, 2004.

CHITARRA, M.I.F.; CHITARRA, A.B. Pós-colheita de frutas e hortaliças - fisiologia e manuseio. 2.ed. Lavras: EDUFLA, 2005 . 875p.

CURRENT, A.R. et al. Efeito do 1-metilciclopropeno em maçãs 'Fuji' armazenadas em atmosfera refrigerada e atmosfera controlada. Revista Brasileira de Agrociência, Pelotas, v.11, n.1, p.91-94, 2005.

DAL CIN, V. et al. The ethylene biosynthetic and signal transduction pathways are differently affected by 1-MCP in apple and peach fruit. Postharvest Biology and Technology, Amsterdam, n.42, p.125-133, 2006.

DE MARTINO, G. et al. 1-MCP controls ripening induced by impact injury on aprictos by affecting SOD and POX activities. Postharvest Biology and Technology, Amsterdam, n.39, p.38-47, 2006.

DURIGAN, M.F.B. et al. Injúrias mecânicas na qualidade póscolheita de lima ácida "Tahiti" armazenada sob condições ambiente. Revista Brasileira de Fruticultura, Jaboticabal, v.27, n.3, p.369-372, 2005.

JOHNSTON, J.W. et al. Temperature induces differential softening responses in apple cultivars. Postharvest Biology and Technology, Amesterdam, v.23, n.3, p.185-196, 2001.

LIU, H.X. et al. The effects of 1-methylcyclopropene on peach fruit (Prunus persica L. cv. Jiubao) ripening and disease resistance. International Journal Food Science and Technology, Oxford, n.40, p.1-17, 2005. 
MAJUMDER, K.; MAZUMDAR, B.C. Changes of pectic substances in developing fruits of cape-gooseberry (Physalis peruviana L.) in relation to the enzyme activity and evolution of ethylene. Scientia Horticulturae, Amsterdam, v.96, n.14, p.91-101, 2002.

MATTIUZ, B.; DURIGAN, J.F. Efeito de injúrias mecânicas no processo respiratório e nos parâmetros químicos de goiabas "Paluma" e "Pedro Sato". Revista Brasileira de Fruticultura, Jaboticabal, v.23, n.2, p.282-287, 2001.

PESIS, E. et al. Ethylene involvement in chilling injury symptoms of avocado during cold storage. Postharvest Biology and Technology, Amsterdam, n.24, p.171-181, 2002.
SAFTNER, R.A. et al. Effects of 1-methylcyclopropene and heat treatments on ripening and postharvest decay in 'Golden Delicious' apples. Journal American Society of Horticultural and Science, Alexandria, n.128, p.120-127, 2003.

VIGNEAULT, C. et al. Embalagem para frutas e hortaliças. In: CORTEZ, L.A.B. et al. Resfriamento de frutas e hortaliças. Brasília:Embrapa Informação Tecnológica, 2002. p.95-121.

WATKINS, C.B. The use of 1-methylcyclopropene (1-MCP) on fruits and vegetables. Biotechnology Advances, Kidlington, n.24, p.389-409, 2006. 